\title{
American Society of Clinical Oncology annual meeting 2015
}

\author{
Wolfgang Eisterer
}

Received: 24 September 2015 / Accepted: 20 October 2015 / Published online: 12 November 2015

(C) Springer-Verlag Wien 2015

The annual meeting of the American Society of Clinical Oncology represents the yearly highlight for the worldwide oncologic community. This year saw around 30,000 participants convening in Chicago where they were presented with a wealth of new data.

This years' motto was "Illumination and Innovation, transforming data into learning". The hot topics 2015 were the immune-checkpoint-inhibitor therapies especially in malignant melanoma and non-small-cell-lung cancer (NSCLC) as will be high-lighted by Georg Pall. In a subgroup of patients with NSCLC, this new treatment was so effective that it replaced docetaxel as second-line therapy after a first-line regimen including a platinum [1].

Rupert Bartsch will outline the enormous efforts in clinical research in the field of breast cancer including Austrian Breast and Colorectal Study Group trial 18 on bone health in post-menopausal women [2] and studies in the setting of Her2-positivity; here T-DM1 alone was as effective as trastuzumab plus docetaxel in the firstline treatment therapy, while dual Her2-inhibition with T-DM1 plus pertuzumab yielded no further benefit [3].

Ewald Wöll demonstrates that immune check point inhibitors also show activity active in esophageal and gastric cancers [4]. C-Met inhibitors were not successful in Phase III trials in gastric cancer [5]. On the other side, first phase II results with regorafenib emphasize a potential role for tyrosine kinase inhibitors in gastric cancer [6].

Sophie Schur and Thomas Brodowicz report on recent results in gastrointestinal stroma tumor and soft tissue sarcomas showing a constant progress in the treatment of both entities as well as paving the way from conventional

\section{W. Eisterer, MD $(\bowtie)$}

Department for Internal Medicine V, Medical University Innsbruck, Innsbruck, Austria

e-mail: wolfgang.eisterer@i-med.ac.at chemotherapy to histology-driven therapy approaches [7-15].

Ultimately, I have the honour to outlay this year's development in colorectal cancer. A phase II trial suggested that tumors with mismatch repair deficiency in the metastatic setting may benefit from treatment with pembrolizumab, another immune check-point inhibitor [16]. Her2-positive Colorectal Cancer (CRC) derive benefit from dual inhibition with trastuzumab and lapatinib after failure of prior lines [17]. In all, two studies show effects of local ablative therapy of liver metastases with radiofrequency ablation and selective targeted radiation [18, 19].

\section{Conflict of interest}

The author declares that there are no actual or potential conflicts of interest in relation to this article.

\section{References}

1. Spigel DR, Reckamp KL, Rizvi NA, et al. A phase III study (Checkmate 017) of nivolumab (NIVO; anti-programmed death 1 (PD-1)) vs docetaxel (DOC) in previously treated advanced or metastaic squamous (SQ) cell non-small cell lung cancer (NSCLC). J Clin Oncol. 2015;33. (suppl;abstr 8009).

2. Gnant M, Pfeiler G, Dubsky PC, et al. Adjuvant denosumab in breast cancer (ABCSG-18): a multicentre, randomised, double-blind, placebo-controlled trial. Lancet. 2015;386:433-43.

3. Ellis P, Barrios CH, Eiermann W, et al. Phase III, randomized study of trastuzumab emtansine (T-DM1) \pm pertuzumab (P) vs trastuzumab + taxane (HT) for first-line treatment of HER2-positive MBC: Primary results from the MARIANNE study. J Clin Oncol. 2015;33. (suppl; abstr 507).

4. Bang YJ, et al. Relationship between PD-L1 expression and clinical outcomes in patients with advanced gastric cancer treated with the anti-PD-1 monoclonal antibody pembrolizumab (MK-3475) in KEYNOTE-012. J Clin Oncol. 2015;33. (suppl; abstr 4001). 
5. Cunningham D, et al. Phase III, randomized, double-blind, multicenter, placebo (P)-controlled trial of rilotumumab (R) plus epirubicin, cisplatin and capecitabine (ECX) as first-line therapy in patients (pts) with advanced METpositive (pos) gastric or gastroesophageal junction (G/GEJ) cancer: RILOMET-1 study. J Clin Oncol. 2015;33. (suppl; abstr 4000).

6. Pavlakis N, et al. INTEGRATE. A randomized phase II double-blind placebo-controlled study of regorafenib in refractory advanced oesophagogastric cancer (AOGC) A study by the Australasian Gastrointestinal Trials Group (AGITG), first results. J Clin Oncol. 2015;33. (suppl 3; abstr 9).

7. Tapp WD. A randomized phase Ib/II study evaluating the safety and efficacy of olaratumab (IMC-3G3), a human anti-platelet-derived growth factor $\alpha$ (PDGFR $\alpha$ ) monoclonal antibody, with or without doxorubicin (Dox), in advanced soft tissue sarcoma (STS). J Clin Oncol. 2015;33. (suppl; abstr 10501).

8. Mir O. Activity of regorafenib (RE) in leiomyosarcomas (LMS) and other types of soft-tissue sarcomas (OTS): Results of a double-blind, randomized placebo (PL) controlled phase II trial.,). J Clin Oncol. 2015;33. (suppl; abstr 10504).

9. Kim C. Clinical pattern and implication of PD-L1 expression in soft-tissue sarcoma). J Clin Oncol. 2015;33. (suppl; abstr 10565).

10. Burgess MA. SARC 028: A phase II study of the antiPD1 antibody pembrolizumab (P) in patients (Pts) with advanced sarcomas.,). J Clin Oncol. 2015;33. (suppl; abstr TPS10578).

11. Demetri GD. A randomized phase III study of trabectedin (T) or dacarbazine (D) for the treatment of patients (pts) with advanced liposarcoma (LPS) or leiomyosarcoma (LMS). J Clin Oncol. 2015;33. (suppl; abstr 10503).

12. Schoeffski P. Randomized, open-label, multicenter, phase III study of eribulin versus dacarbazine in patients (pts) with leiomyosarcoma (LMS) and adipocytic sarcoma (ADI).). J Clin Oncol. 2015;33. (suppl; abstr 10542).
13. Joensuu H. Three vs. 1 year of adjuvant imatinib (IM) for operable high-risk GIST: The second planned analysis of the randomized SSGXVIII/AIO trial). J Clin Oncol. 2015;33. (suppl; abstr 10505).

14. Chandrajit PR. Adjuvant imatinib (IM) for patients (pts) with primary gastrointestinal stromal tumor (GIST) at significant risk of recurrence: PERSIST-5 planned 3-year interim analysis.,). J Clin Oncol. 2015;33. (suppl; abstr 10537).

15. Blay JY. Final results of the multicenter randomized phase II PAZOGIST trial evaluating the efficacy of pazopanib (P) plus best supportive care (BSC) vs BSC alone in resistant unresectable metastatic and/or locally advanced gastrointestinal stromal tumors (GIST).). J Clin Oncol. 2015;33. (suppl; abstr 10506).

16. Le DTL, Uram JN, Wang H, et al. PD-1 blockade in tumors with mismatch repair deficiency. 2015 ASCO Annual Meeting. J Clin Oncol. 2015;33. (suppl; abstr LBA 100). Late Breaking Abstract 100.

17. Siena S, Sartore-Bianchi A, Lonardi S, et al. Trastuzumab and lapatinib in HER2-amplified metastatic colorectal cancer patients (mCRC): The HERACLES trial.). J Clin Oncol. 2015;33. (suppl; abstr 3508).

18. Ruers T, Punt CJA, van Coevorden F, et al. Radiofrequency ablation combined with chemotherapy for unresectable colorectal liver metastases: Long-term survival results of a randomized phase II study of the EORTC-NCRI CCSG-ALM Intergroup 40004 (CLOCC).). J Clin Oncol. 2015;33. (suppl; abstr 3501).

19. Gibbs P, Heinemann V, Sharma NK, et al. SIRFLOX: Randomized phase III trial comparing first-line mFOLFOX $6 \pm$ bevacizumab versus mFOLFOX $6 \pm$ selective internal radiation therapy \pm bevacizumab in patients with metastatic colorectal cancer.). J Clin Oncol. 2015;33. (suppl; abstr 3502). 